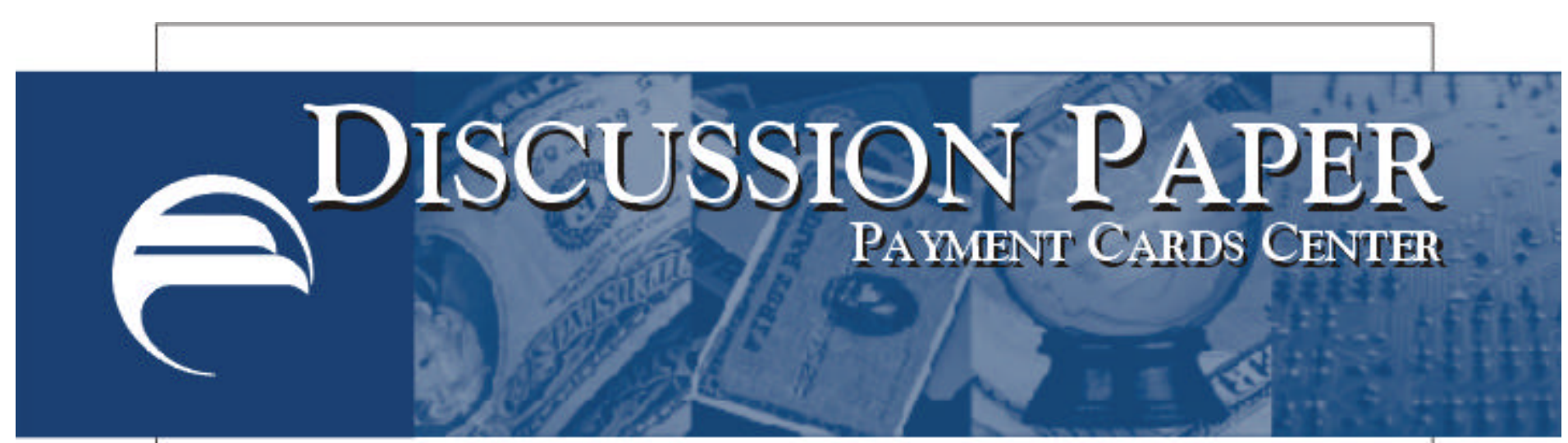

\title{
Innovations in Small Dollar Payments ${ }^{1}$
}

\author{
Peter Burns \\ Anne Stanley
}

October 2001

Summary: On September 25, 2001, the Payment Cards Center of the Federal Reserve Bank of Philadelphia sponsored a workshop on innovations in small dollar payments. The moderated discussion was led by Richard Corl, an entrepreneur with 25 years of experience in the electronic payments industry. ${ }^{2}$ From his perspective as a director of Ecount, a small dollar payments innovator, Corl described a range of challenges and opportunities for innovators in their quest to convert small dollar cash and check payments into electronic transactions. In addition to broad market issues, he described a number of specific emerging applications. This paper is a summary of Corl's presentation.

\footnotetext{
${ }^{1}$ The views expressed here are not necessarily those of this Reserve Bank or of the Federal Reserve System.

${ }^{2}$ In 1976 Corl founded the TeleCheck Services network, now a division of First Data Corporation. In 1992 he became a co-founder of Princeton eCom Corporation, a leader in the electronic bill payment industry, where he served in a variety of executive positions until August 2000. Corl now plays a senior strategic role in several young, innovative companies in the electronic payments industry. Corl has been a featured speaker at many industry forums held by the National Automated Clearing House Association (NACHA), Bank Administration Institute (BAI), American Bankers Association (ABA), and Treasury Management Association (TMA).
}

\section{Federal Reserve Bank of PhiladelPhia}




\section{Background}

The workshop opened with an overview of U.S. personal consumption expenditures and a breakdown of associated payment vehicles. Using data from 1999, Corl noted that paper-based transactions (primarily cash and personal checks) accounted for 69 percent of consumer expenditures. Card-based transactions (including credit, debit, and stored-value) accounted for 28 percent of consumer expenditures and electronic payments (telephone, computer, Internet, and $\mathrm{ACH}$ ) accounted for 3 percent of payment methods used.

These numbers clearly illustrate that cash and checks dominate as the payment method of choice, and the long predicted "checkless society" remains an elusive goal. Card-based transactions have shown significant growth over the past 20 years, largely because of the success of the now ubiquitous credit card. More recently, debit cards have begun to gain popular acceptance, with growth rates far outstripping those of the traditional credit card. On the other hand, stored-value cards (smart cards) have received a lot of attention in the past few years as an attractive alternative payment vehicle, but at this point, the anticipated growth has not materialized. Despite the Internet and various ACH initiatives, the small 3 percent share made up by electronic payments is perhaps the most surprising piece of information. Corl cautioned that the 1999 data are now nearly two years old and we should expect to see greater growth in the electronic media in the future. Nevertheless, he emphasized that the pre-authorized $\mathrm{ACH}$ debit product has far from lived up to its potential for effecting consumer payments. Corl believes that the relative complexity of setting up the accounts plus the inflexibility in timing payments has led to consumer resistance. On the positive side, he noted that only in the last few 
years have banks and billers begun to effectively market $\mathrm{ACH}$ - based products and improve service delivery. Anecdotal evidence suggests that many firms that initially experienced difficulty in correcting errors or providing information to consumers have now invested in customer service call centers to better support their product offerings.

Corl concluded that despite lack of early success, he believes there is tremendous opportunity for electronic payment vehicles to occupy an increasingly important role in consumer payments. This is especially true in the small dollar payment area where low cost and inherent capability to capture information provide unique advantages over other payment media.

\section{Innovation in Small Dollar Payments}

Before examining innovations in small dollar payments, we should consider the size of the opportunity and the range of payment types. Corl suggests that defining "how small is small" is not terribly meaningful. Going back to the 1999 personal consumption expenditure data, he noted that there were 47 billion cash transactions with an average size of $\$ 20$. If we add to this the portion of the 29 billion personal checks written that year that fall into the small dollar category, it is clear that there is ample opportunity for innovators who are able, to profitably displace even a small fraction of this volume.

What then are the payment types underlying these transactions, or who is paying whom? Understanding the parties involved is the next critical step in defining the requisite business models for innovative solutions. While not intended to be exhaustive, Corl's list included five areas of opportunity:

- Displacement of small cash payments

- Electronic bill payment 
- Person-to-person payments

- Business-to-consumer payments

- Web shopping

While traditional credit cards play a role in a number of the small dollar markets, Corl believes that pure electronic payment alternatives offer the most promising solutions. In large part this is a cost issue with the complex credit card infrastructure far more expensive than web-based applications with firms operating in simpler closed systems. In the typical credit card environment, transactions are processed through multiple parties: the merchant, the merchant processor, VISA or MasterCard, and the card - issuing bank. In contrast, most of the alternative electronic methods of payment are closed systems that adjust balances internally, eliminating the multiple transaction flows and resulting fees. Corl concluded by stating "that a market exists to convert small cash payments into electronic media and with at least 47 billion of cash transactions available there are clear incentives for firms to develop innovative payment solutions to address customer segments in the businesses-to-consumer, consumer-to-businesses, and consumer-consumer categories."

\section{Innovation in the Marketplace}

Having defined the broad structure for small dollar payments, Corl highlighted several examples of the various categories outlined above:

Displacement of Small Cash Payments. Among the innovative approaches recently introduced are the Mobil Oil Speed Pass used at gas pumps, EZ Pass now used for turnpike toll payments, the 2 Scoot 
McDonald's Drive-Through Program, and USA Technologies' electronic wireless vending machines.

The now familiar EZ Pass provides one example of how new electronic payment schemes provide sufficient value to spur infrastructure investment and consumer adaptation. Having E-Z Pass's electronic toll collection (ETC) technology installed in your car, account information on an electronic tag is read by a receiving antenna at the toll plaza. The toll is then electronically deducted from your prepaid account. The benefits of E-Z Pass are convenience for the consumer and an increased processing ( 250 to 300 percent) of vehicles per lane in a cost-efficient manner.

Electronic Bill Presentment and Payment (EBPP). EBPP has been something of a Holy Grail for billers and banks hoping to improve the efficiency of the billing process, broaden acceptance of electronic banking, and create enhanced customer contact opportunities. To date, the so-called "killer app" has yet to materialize.

Despite growth in Internet usage by the public, most estimates suggest that fewer than one million households view and pay their bills online, although a larger number pay bills on the Internet that are received in the mail. According to Corl, who led one of the industry's pioneering efforts in this area, the complexity of the process and data management issues have been grossly underestimated. Furthermore, he contends that innovators have largely failed to appreciate the strategic relevance billers 
have come to place on billing as a customer contact opportunity. Last, he cites the difficulty in creating a compelling value proposition for consumers that will lead to more widespread adoption. While no dominant solution in electronic bill payment has evolved to date, there are four primary models in the marketplace:

- Bank sites that provide direct debit from customer accounts.

- Biller-direct services that generally provide e-mail advice of bills and then offer a range of payment alternatives.

- Internet portal services that provide links to a range of payment alternatives.

- Pre-authorized ACH debit programs that have date-certain debits to customer bank accounts.

Person -to-Person Payments. PayPal is perhaps the most familiar of these schemes. PayPal has achieved most of its success as a payment vehicle in the Internet auction arena, most notably with eBay. In the eBay environment, a consumer with an active PayPal account may purchase an item on eBay. The buyer then advises PayPal and provides their e-mail address. PayPal in turn advises the seller via e-mail that the buyer has a funded account and ultimately transfers the funds from the buyer to the seller's PayPal account. PayPal sits in the middle providing security and account anonymity to both parties in the transaction. Unfortunately for PayPal, it has had little success in encouraging use outside the auction 
environment. Gaining a consumer as a regular user has proved challenging, in part because of the unique nature of the motivating transaction. Corl believes that a better model for the person-to-person market is to promote its use among communities (such as members of a group owing each other money or dues, etc.) or for college students needing regular fund transfers among themselves and quick access to funds from their parents or as a way to regularly send money overseas.

Business-to-Consumer Payments. There are many examples of small dollar (and not so small dollar) payments made by businesses to consumers that might well be more efficiently managed over electronic media. In the discussion, Corl spoke of several real examples where electronic payments are displacing cumbersome paper-based processes, resulting in efficiencies and, often, enhanced information capture. Examples include web gift certificates, incentive reward payments, loyalty reward programs, and payroll applications for firms with large numbers of temporary employees. Ecount's webcertificate offering illustrates one example where electronic payments not only result in cost savings but also enhance the general service offering. Webcertificates allow a firm to send an electronic gift card with an associated dollar value for a variety of purposes, ranging from rebates to loyalty rewards or similar "gifts" to customers or employees. The certificate and notification of funds in an established Ecount account are sent instantly (or at a designated date) to 
the recipient via e-mail. Once the webcertificate is claimed, the recipient can spend his Ecount funds at any online merchant that accepts a credit or debit transaction from MasterCard, the Ecount partner. The recipient may also request a physical card to access his funds through an ATM or to use for offline purchases, again up to the limit of his Ecount balance, which, of course, can be funded beyond the original deposit. As Corl noted, the firm benefits because costs are lower than for payments made via checks and recipients gain access to something close to cash at Internet speed

Web Shopping. Credit cards are the payment vehicle of choice for most web shoppers. However, Corl argues that as web sites move to transaction payments for archival retrieval services or similar information requests, the resulting small dollar payments on credit cards will prove economically prohibitive. This will open up the opportunity for innovative applications of low cost electronic payments via pre-funded or stored-value-like accounts from service providers such as Ecount and others.

\section{Going Forward}

The workshop concluded with Corl noting that while the 3 percent figure for consumer electronic payments may appear low, innovative entrepreneurs are hard at work, and we should expect significant future growth in electronic applications. The continuing growth in Internet usage by households across all demographic segments and 
the sharp decline in telecommunications and computer-processing costs all provide further stimulus to entrepreneurial initiatives. To be successful, though, contenders in this marketplace must understand the customer segments being addressed and ensure that they offer compelling value propositions to both parties in the payment transaction.

As a final caveat, Corl noted that much of the innovation in electronic payments is coming from firms outside the traditional banking or insured depository environment. For the most part, these firms do not have the same depth of controls that exist in the traditional regulated financial services industry. To date, the dollars have been small, and no significant problems have emerged. At the same time, there have been several publicized examples of security breaches and data theft, though, again, the repercussions have been contained. In the end, trust in a payment system is the critical success factor, and as increasing levels of dollars and customer information flow through these unregulated environments, the risks of a major breakdown increase. This could well have a dampening effect on consumer confidence in the new payment technologies or perhaps lead to a change in market structure favoring banks or those firms with demonstrated ability and capacity to protect their customers. All that said, Corl's view is that we will see dramatic change in the electronic marketplace and significant growth in the 3 percent share of consumer payment activity. 